Complutense Journal of English Studies

ISSN: 2386-3935

http://dx.doi.org/10.5209/CJES.61754

\title{
Early Bilingual Education in a Monolingual Environment. Showcasing Polish Families
}

\author{
Piotr Romanowski ${ }^{1}$
}

\begin{abstract}
The overriding aim of the article is to present, evaluate and discuss the effectiveness of early bilingual education in a monolingual environment, such as Poland. As opposed to situations where parents use two languages due to their different nationalities and backgrounds or instances of employing foreign nannies to address children in another language (usually their own L1), this paper will focus on a controversial issue of using a foreign language (L2) by a parent and speaking it to a child in a natural way. The purpose of the theoretical section is to depict the role of parents, the possible strategies used in raising children bilingually as well as potential problems to be encountered in the process. The subsequent empirical part outlines the results of analysed case studies collected from 22 Polish families who have successfully employed such a model of language learning and communication with their children.
\end{abstract}

Keywords: early bilingual education, bilingualism, bilingual upbringing, strategies of communication.

\section{[es] La educación bilingüe temprana en contextos monolingües. El caso de las familias polacas}

Resumen. El objetivo primordial de este artículo es presentar, evaluar y debatir la efectividad de la educación bilingüe temprana en un entorno monolingüe, como es el de Polonia. Frente a situaciones en las que los padres usan dos idiomas debido a sus diferentes nacionalidades u orígenes, o a casos en los que niñeras extranjeras hablan a los niños en otro idioma (generalmente su propia L1), este trabajo se centra en el controvertido asunto del empleo de un idioma extranjero (L2) por parte de un progenitor y su utilización de forma natural para dirigirse al niño. La sección teórica plasma el papel de los padres, las posibles estrategias utilizadas en la crianza de los niños de forma bilingüe y los posibles problemas que se pueden encontrar en el proceso. La parte empírica posterior analiza los resultados de los estudios de caso recopilados: 22 familias polacas que han empleado con éxito este modelo de aprendizaje de idiomas y comunicación con sushijos.

Palabras clave: educación bilingüe temprana, bilingüismo, educación bilingüe, estrategias de comunicación.

Contents. 1. Introduction. 2. Early bilingual education and its trajectories in Poland. 3. A family as the primary socialising agent in second language acquisition. 4. Communication strategies in the family. 4.1. One Parent One Language (OPOL). 4.2. Minority Language at Home (mL@H). 4.3. Time and Place (T\&P). 4.4. Mixed Language Policy (MLP). 5. Possible issues and suggested solutions. 5.1. An imperfect L2 spoken by parents. 5.2. A lack of an appropriate word. 5.3. The use of the 'wrong'language. 5.4. The child rejecting L2. 5.5. Hostility of the monolingual environment. 6. The study. 6.1. Objectives. 6.2. Methodology. 6.3. Research findings. 7. Conclusion.

1 School of Specialised and Intercultural Communication, Faculty of Applied Linguistics, University of Warsaw E-mail: p.romanowski@uw.edu.pl 
How to cite this article: Romanowski, P. (2018) Early Bilingual Education in a Monolingual Environment. Showcasing Polish Families, in Complutense Journal of English Studies 26, 143-164.

\section{Introduction}

In many environments, children grow up bilingual, or even multilingual, mainly because two or more languages are spoken in their surroundings. Obviously, language acquisition is more spontaneous when it is used in authentic situations of communication. The learners can thus activate their natural faculty of acquiring languages to a maximum (Romanowski 2016).

Despite some views that the most natural context for a child is a monolingual environment, it needs to be emphasised that monolingualism constitutes a widespread stereotype, especially in countries with a mainstream culture such as the United States (Singleton \& Aronin 2007; Otwinowska 2015). People using only one language exclusively are hard to be found (Cook 2002: 23). In addition, Gupta (1994: 161) claims that in some parts of the world families are accustomed to using two or three languages in their households interchangeably so as to enhance their children's proficiency in more than one language, and it is the usage of one language that starts to be regarded as rare there. Hence, in recent years, bilingual education has proved very effective in various situations at different geographical locations, including Canada, the United States, Germany, Spain, Belgium, Hong Kong, Singapore, Australia - to recall only the names of very few places.

The main purpose of this article is to focus on evaluating and discussing the effectiveness of early bilingual education in monolingual Poland. As opposed to situations where parents use two languages due to their different nationalities and backgrounds or instances of employing foreign nannies to address children in another language (usually their own L1), this paper will discuss a controversial issue of using a foreign language (L2) by a parent when interacting with a child. The central assumption of the model of communication is that only one of the parents uses a foreign language in daily interactions with a child while the other sticks to the community's dominant language (Saunders 1988; Döpke 1992; Jimenez 2011; Szramek-Karcz 2014). Hence, it is also assumed that such a model of communication constitutes one of the possible manners leading to raising a bilingual child. The purpose of the theoretical section is to depict the role of parents, the possible strategies used in the bilingual upbringing of children as well as potential problems to be encountered in the process. The subsequent empirical part outlines the results of analysed case studies collected from 22 Polish families who have successfully employed their model of communication with children.

\section{Early bilingual education and its trajectories in Poland}

Hickey (2013) defines early bilingual education as a phenomenon referring to a number of models of early years education offered to children aged between two and about five or six years. It operates at the critical nexus between home and school, offering children an opportunity to acquire a second language or to enrich their home language. Preschool education has long been recognised as promoting children's social and intellectual development, and in many countries children are also offered 
the opportunity to attend preschools where the medium of instruction is another language such as a heritage language, a non-dominant local language, or a dominant language of another country. The models used vary, reflecting the different needs of multilingual countries as well as provision for migrant populations.

To provide a better overview of what early bilingual education involves, perhaps it would be essential to first make a distinction into ESLA, MFLA and BFLA. Without a prior discussion of the three terms, it might somehow seem hard to understand how children acquire languages from birth. De Houwer (2009a) highlights the fact that Bilingual First Language Acquisition (BFLA) is the development of two first languages with no chronological difference regarding when they start to hear them. On the other hand, in Monolingual First Language Acquisition (MFLA) children hear just one language from birth - their L1. Last but not least, Early Second Language Acquisition (ESLA) occurs when monolingual children's language environments change in such a way that they start to hear a second language (L2) with some regularity over and above their L1. All the three learning contexts share one important aspect - namely, children acquire the languages without formal instruction.

For each of the language learning contexts, different effects on early language development can be noticed. BFLA children learn to understand two languages simultaneously. When they start to speak, they usually say words and sentences in both languages. By contrast, MFLA children learn to understand and speak one language only. Finally, ESLA children initially learn to understand one language and start speaking in one language only (L1), which is followed by understanding a second language (L2) also spoken at some point later.

Li Wei (2011) indicates that one prominent feature of English in Europe today is the increasing number of children with an L1 that is not English who acquire English at a very early age (i.e. before the age of three) when their L1 is not yet fully developed. This is particularly the case of children born to parents who are not English L1 speakers and who are exposed to languages other than English at home.

In Poland, early bilingual education has become quite popular as there are more and more mixed couples deciding to move here every year. In addition, as the country's economic status has changed, a number of well-off parents hire foreign nannies who flock to the country offering Polish children the possibility of learning a foreign language or even becoming bilingual from birth in return for a chance of experiencing a new culture, visiting the places and learning Polish. However, it should be emphasised that some couples, who have either graduated from language studies or learnt the language abroad, take advantage of a very controversial model of communication with their children which involves using a second language while addressing their children. Whilst official statistics are hard to obtain, media reports have led us to believe that there has been a considerable growth of such practices in the last decade although very many instances of this model of communication were noticed even in 1970's and 1980's across Eastern Europe, which at the time was situated on the other side of the iron curtain.

\section{A family as the primary socialising agent in second language acquisition}

One of the most crucial aspects to consider in an attempt to raise a bilingual child is adjusting one's expectations when it comes to the child's linguistic attainment. Too 
high expectations may lead to frustration and abandonment of L2 when difficulties arise (De Houwer 2009a; Jessner 2008). Some parents would want their children to be able to freely communicate in a language, whereas others may want to bring their children in contact with it to prepare them for a formal instruction in the language which they will receive at school. Both cases require a different amount of linguistic input, which in turn, will result in different levels of competence in a language (Grosjean 2009: 4; Rosenback 2017). Although it might sometimes seem that there has been little success, parents ought to stay consistent in their use of L2 and not resign, because even if no apparent outcomes can be observed, the passive knowledge of a language will constitute a foundation to build on later in life (Saunders 1988: 44).

Out of a range of factors determining the success of bilingual upbringing is the child's motivation to speak the second language. In many families this may pose a particular challenge, as the use of two languages does not result from the natural need to communicate with both parents as in the case of children from mixed marriages. Grosjean (2010: 171-173) asserts that if the parent is not a native speaker of a language, the child may object to speaking L2 to them, as they can as easily use L1. In such circumstances an additional motivation may be required, i.e. being able to read favourite books in their original language version, watching favourite cartoons and singing songs together with parents, being able to communicate with peers in a bilingual kindergarten or school, or with an L2-speaking babysitter, keeping in touch with monolingual relatives or travelling abroad (De Houwer 2009b). The latter is particularly useful in monolingual environments as it allows children to see for themselves that L2 functions the way L1 does and that their efforts to acquire it are worth it (Saunders 1988: 139). It is essential to note that when English is L2 - the language recognised worldwide - children are surrounded by proofs that this is an important thing to learn, starting from English songs and films on the radio and TV, up to peers learning English as L2 at school. Last but not least, parents ought to keep in mind that learning L2 should be an attractive experience and not be imposed on the child, as in this way they may become discouraged from using it (Zurer Pearson 2008: 307).

In addition to catering for the need of a good reason to learn L2, it is of paramount importance to provide the child with appropriate conditions for the learning to take place, both about quantity and quality of the language input received by them. The latter means that the contact with both languages should consist of meaningful interactions in which the child is an active participant. Not only should a parent introduce L2 to their child but also sustain their contact with it (Zurer Pearson 2008: 168-170). It is significant to consider where the input is going to come from, and whether there are sufficient resources available. Saunders (1988:248-255) enumerates a number of sources to rely on for an additional linguistic input:

- reading storybooks to children, which has an added advantage of familiarising children with different varieties of language,

- providing children with magazines to support their interests,

- buying monolingual and bilingual dictionaries to foster independent language development,

- listening to songs and audiobooks in L2 so that the child can get used to different accents,

- watching TV programmes for children and programmes designed for language learners, 
- taking advantage of facilities outside home where L2 can be understood,

- sending children to bilingual schools and language camps,

- travelling abroad, which has an added advantage of total immersion in a language and a possibility of making L2-speaking friends,

- keeping in touch with children from abroad (letters, e-mails, telephone conversations),

- organising playgroups with other children who speak L2,

- hiring a native speaker of L2 as a babysitter.

It has to be noted that the child is not the only one who requires support. As the constantly changing world influences the languages, new expressions and idioms are being coined on a regular basis. For this reason, it is essential that parents take time to develop their knowledge in a language (Saunders 1988: 256). As in the case of children, it can also be achieved through radio and TV, but it is also advisable for the parent to keep in touch with native speakers of L2, should the need arise to seek linguistic advice (Baker 2014). Another aspect in which parents from monolingual environments should seek support goes beyond the language itself. To be understanding towards their children in their endeavours to acquire two languages simultaneously, parents ought to broaden their knowledge on the topic of bilingualism by reading the relevant literature. This can also be helpful in a way that they will know what to expect and will not be discouraged by seemingly disturbing phenomena which are related to bilingual upbringing (Grosjean 2010: 214; Saunders 1988: 255). Another option would also be the possibility of meeting with other bilingual families and establishing a support group for parents (Paradowski \& Michałowska 2016: 55).

A crucial element in catering for the child's need for meaningful interaction in both languages are conversations. In order to internalise chunks of language, the child needs a sufficient language input to analyse. Having heard a given unit of language a number of times in different contexts, the child will be able to use it correctly. It is suggested that about $30 \%$ ( 25 hours a week) of all interactions should take place in L2, 20\% (15 hours a week) being the absolute minimum. However, it has to be acknowledged that the most efficient acquisition takes place when the child is addressed directly, and therefore actively engaged in an interaction. Active sources of language (talking, reading, playing) are better than the passive ones (TV), as communication with other people constitutes an additional motivation to learn L2 (Grosjean 2010: 210; Rosenback, 2017). To encourage the participation on the part of the child, it is advisable to comment on the events and pictures while reading books as well as to interpret the emotions of the characters. Due to natural repetition, children internalise whole bits of language.

Apart from providing children with linguistic input, it is equally important to invite their attempts to communicate by listening to them actively and letting them talk. It is advisable to ask open-ended questions, show interest in the content of utterances, help them when they cannot come up with an appropriate word to use and praise their efforts in the form of I-message ("I'm glad that you speak my language"). When correcting mistakes, one should be careful not to break the flow of the utterance (Komorowska 2005: 234). Döpke (1986) advises applying the "child-centred mode of interaction", which means being open and responsive as well as sustaining the conversation by focusing on its content and not on the mistakes. Since bilingual parents tend to mix their languages, it is worth providing the child with a possibility 
to interact with a monolingual L2 speaker. In this way, the child learns to adjust their speech to the circumstances, as code-switching will not be understood. The child has no choice but to use L2, at the same time receiving a high-quality language input, not influenced by code-switching and interference, which frequently characterises the speech of non-native speakers (Grosjean 2009: 3).

As far as error correction in the child's speech is concerned, certain rules of formal L2 instruction are of application in this context. It should be noted that error correction has to be subtle so as not to discourage the child form their attempts to communicate. Although it is advisable to focus on the content of the utterance and not on its form, some error correction may prove to be necessary (Komorowska 2005: 234-235). The easiest way to correct mistakes is for the parent to rephrase what the child has said and build their answer based on it (the so-called recasts) (Pearson, 2008: 110). If an error is caused by distraction or rush, and the parent knows that the child is familiar with the correct form and able to use it, it is enough to direct the child's attention towards the mistake and give them the opportunity to self-correct. Komorowska (2014) suggests some possible solutions, e.g. repeating what the child has just said up to the point where the mistake occurred, using hesitation in the tone of voice, asking about the content of the wrong sentence, or even proposing a set of forms for the child to choose from. However, if the parent wants to offer correction themselves, the best way would be to repeat correctly what the child has said and elaborate on it. Only in this way will they be exposed to the correct form and encouraged to continue the conversation.

\section{Communication strategies in the family}

Having considered both the motivation for learning two languages and the possible sources of input in each of them, it is advisable to decide on the strategy of communication in the family: which parent will use which language to communicate with the child, in which language will the parents talk to each other, which language will be used when addressing the extended family and other monolingual speakers, which language will be used outside the home, how will the attention between the languages be divided and so on (Zurer Pearson 2008: 189-195; Baker 2014; Festman, Poarch \& Dewaele 2017).

It has to be acknowledged that there is no one best strategy which would prove to be successful in all families. Each family has their own circumstances and develops their own unique strategy with time. In addition, it might be necessary to adapt the chosen strategy to the changing linguistic circumstances. For instance, when the child starts a monolingual kindergarten or school and L1 begins to prevail in their environment, it may be necessary to increase their exposure to L2 and therefore change the previously adopted strategy. What does not change is the need to consequently provide the child with an L2-rich environment. It poses a significant challenge even for native speakers of a minority language surrounded by the majority language, let alone non-native speakers (Paradowski \& Michałowska 2016: 52). The following strategies, however, are supposed to offer an idea of how communication in the family can be organised, and they can be modified to suit the needs of a given family. As mentioned by Szramek-Karcz (2017), the parent ought to feel good about their choice, and it does not involve speaking L2 at all costs. If the parent feels the 
need to do so, they may make an exception and switch to L1. They should not force their child to speak L2, either. The key to success is the parent's positive attitude, positive expectations regarding the effects of bilingual upbringing and the ability to come to terms with one's emotions. The parent ought to feel that they give their child what they consider to be best for them and, although it is advisable to reduce such situations to the minimum, they should not feel guilty if there are times when they fail to be consistent in their choice of language.

\subsection{One Parent One Language (OPOL)}

In the families who adopt the One Parent One Language strategy both parents speak a different language to their child (Grosjean 2010; Kurcz 2006; Baker 2014; Rosenback 2015). An advantage of this strategy is that the child learns to associate a language with the parent and, therefore, is better able to decide which language to use when addressing each of them. As a result, the parents know which language they may expect from the child, which enhances the understanding of the child's first utterances (Arnberg 1987:89; Pearson 2008: 186). If parents are consistent in their use of language, the child may develop what Grosjean (2010: 183-184) calls a person-language bond, which, if not respected, may adversely affect the child.

It has to be noted that the time which the child spends with each parent should be divided equally. If due to working hours or other conditions, one parent spends more time outside the home, the input in one of the languages may prove to be insufficient (Zurer Pearson 2008: 303). The careful consideration of a language which parents speak to each other may help to balance the child's exposure to both languages, one of which may be dominated by the language of the community (Paradowski \& Michałowska 2016: 51). An undeniable advantage is a situation in which both parents understand both languages. This way everyone can participate in a conversation at all times. Otherwise, it is advisable to translate or summarise what has been said for the other parent, so that no one is excluded from the conversation (Saunders 1988: 56).

On the one hand, the OPOL strategy is recommended as an effective approach, as compared to other strategies, because each of the languages is equally reinforced (Saunders 1988: 34; Pearson 2008: 302). However, this is only true as long as the child spends most of the time at home with the parents. As the child starts kindergarten or school, L1 exposure increases and it may become a dominant language (Baker 2010).

\subsection{Minority Language at Home (mL@H)}

If both parents are fluent speakers of L2, they may decide to adopt the Minority Language at Home strategy, where both parents speak L2 at home and L1 outside the home. A place is considered to be a factor which triggers the language switch. This strategy provides the child with greater exposure to L2 than in the case of OPOL (Grosjean 2009; Kurcz 2006; Rosenback 2015; Pearson 2008: 186-187).

There exist certain variations of the Minority Language at Home strategy. Some parents do not teach L1 to their child at all, as they are of the opinion that the child is bound to naturally acquire it when they start kindergarten or school. Such an approach results from the parents' decision to increase the child's exposure to L2 even further. One of such modifications is called Minority Language Immersion, when L2 
is spoken by both parents at all times (at and outside home), except in the presence of those who do not speak L2 (Ramjoue 1980). The second variation also takes advantage of the strong position of the language of the environment, and it can be observed in the families where parents speak only L2 at all times, and after 4-5 years, when L2 becomes considerably established, they switch to L1. Grosjean (2010: 207, 209) calls this approach 'one-language-first' strategy. It is, however, difficult to imagine such radical modifications to mL@H strategy in certain contexts. A lack of L1 exposure could pose great difficulties for the child in keeping up with the acquisition of knowledge at school without the proper knowledge of the language of instruction.

\subsection{Time and Place (T\&P)}

The Time and Place strategy is often used to complement other strategies. A trigger to a language shift may be travelling to a country where L2 is spoken or visiting a monolingual family, friends, etc. On a daily basis, it involves speaking L2 at particular times of the day or days of the week (Grosjean 2010; Kurcz 2006; Zurer Pearson 2008). Rosenback (2015) suggests this strategy as a good option for parents who do not feel comfortable speaking L2 to their children at all times, and whose language abilities may not allow for it. With time, the amount of L2 spoken to the child may be increased. Time and Place strategy is often used in bilingual schools (immersion programmes) where the language of instruction may differ according to the subject, time of the day, etc. (Grosjean 2010; Baker 2010).

\subsection{Mixed Language Policy (MLP)}

In the Mixed Language Policy strategy both languages are used interchangeably, and the choice of language depends on the topic discussed, participants in the conversation, the language one is addressed in, etc. (Grosjean 2010: 207; Zurer Pearson 2008: 187189). Since in many situations language choice is mostly accidental, there is a risk of the child not getting a sufficient input in one of the languages, most likely in L2. In this case, the parent ought to ensure that the amount of input the child receives is similar in both languages (Auer \& Li Wei 2006; Grosjean 2010: 210; Rosenback 2015).

Irrespective of the chosen strategy, a family does not have to resign from applying it in special circumstances, for instance in the presence of a monolingual person (communication outside the family). In such situations, L2 can still be used but the conversation needs to be translated into or summarised in a language understood by the people present (Zurer Pearson, 2008: 195) Refraining from the use of L2 means that the child's contact with it will be reduced. The consistent use of L2 teaches children to get rid of inhibitions about speaking a different language and shows that there is no reason to be embarrassed about it (Saunders 1988: 107).

\section{Possible issues and suggested solutions}

\subsection{An imperfect $L 2$ spoken by parents}

As far as accuracy in a language is concerned, Zurer Pearson (2008: 147) claims that even if L2 spoken by the parents is not flawless, the child can process the language 
outside the input which they receive and reconstruct correct grammar rules. The author describes the study conducted by an American professor of neurology Elissa Newport, who specialises in language acquisition. The study has shown that a deaf child learning a sign language from their deaf parents who made grammar mistakes, was able to develop a much higher level of grammatical correctness than their parents. It is worth noting that occasional mistakes can be observed even in the speech of native speakers of a language. For that reason it is crucial to provide the child with additional sources of L2, which will compensate for the possible shortcomings in the parent's speech (Szramek-Karcz, 2017).

\subsection{A lack of an appropriate word}

It is worth sensitising children to the fact that no one knows all the words even in their native language. This knowledge has an added advantage of making children aware of the possibility of consulting a dictionary when needed and, therefore, enables them to develop their language skills independently (Saunders 1988: 134-135). So as not to allow the unknown words hinder daily communication, until the parent has a possibility of consulting a dictionary or a native speaker, it is possible to describe what is meant using other words. After the parent has checked a needed word, it may be necessary to show the child how to use it. This can be done in a way typical of teaching and learning languages such as providing synonyms, definitions, putting a word in a sentence so as to provide a context, etc. Should an incorrect word or pronunciation be provided, it is crucial to correct it before it becomes established in the child's vocabulary.

Not only mistakes but also the style of the language spoken outside its native environment may distinguish it from the language of a native speaker. An issue of passing on an 'imperfect' language was also mentioned by the parents, who participated in one of the case studies conducted by Pearson (2008: 256). They admitted that in addition to making occasional grammatical mistakes, they sometimes happened to lack appropriate words and had difficulty providing synonyms or paraphrasing. It is also quite natural that a language used by the parents to "describe" the world for children may differ from the language which would be used in the same situation by a native speaker. This is why it is crucial for parents to develop their language skills constantly. Taking all this into consideration, it is possible that L2 spoken by a child from a monolingual environment will differ from the language spoken by a native speaker of L 2 .

\subsection{The use of the 'wrong'language}

If the mixing of languages by the child does not result from the developmental stage they are currently at, it may be the reflection of parental linguistic behaviour, or it may simply be caused by the insufficient knowledge of one of the languages and the need for a more accurate expression of thought (Grosjean \& Li 2012; Saunders 1988: 79; Zurer Pearson 2008: 199-201).

If resorting to L1 is caused by the insufficient knowledge of L2, the assistance on the part of the parent, such as providing the child with a needed equivalent in L2, may be offered. According to Saunders (1988: 131-132), it is advisable that both parents assist in both languages, even if it is required in a language which they do not usually 
use in communication with the child. Restricting this kind of assistance to one parent only may hinder the child's natural curiosity about the languages and slow their linguistic development. So as to enhance the child's exposure to L2, it is also worth deliberating a change in the previously applied strategy of communication in the family. For instance, parents may decide to choose a day in a week or a time of the day when only L2 will be spoken by all the members of the family (Baker 2014).

If, despite the sufficient competence in L2, the child still chooses to address the parent in a different language than agreed upon, the parent may try and encourage the child to switch back to a desirable language. Lanza (1997) proposes a few strategies concerning the parent's reaction to the use of the "wrong" language by the child. If the parent wishes to direct the child's attention towards the "correct" language, they may use this language to say that they do not understand, to ask about the content of the utterance, or to repeat what has been said. Another possibility is to ignore the language switch and continue the conversation it the correct language. Sometimes the parent may wish to agree on the language change and continue the conversation in the language proposed by the child. Lanza (1997) stresses the fact that asking for repetition or clarification happens naturally in any conversation, and is, therefore, a non-intrusive way of reverting to the desired language. It has to be noted that these strategies can only be used in moderation and when the child is old enough to distinguish between the languages. Otherwise, they may be discouraged from using L2 (Saunders 1988: 125). Other circumstances in which the parent should not insist on the use of L2 are the situations which are emotionally difficult for the child. If the child hurts themselves in a playground, it is only natural to react in L1. When the emotions subside, L2 can be used to recount what happened (Szramek-Karcz 2016).

If parents are consistent in their language choice, the mixing of the languages by the child should be significantly reduced with time (Saunders 1988: 123). The parents themselves underline the significance of such consistency. The study conducted by Paradowski \& Michałowska (2016: 56-57) has shown that when asked about the reflections concerning the aspects of bilingual upbringing which could have been approached differently, the majority of parents regretted not being consistent enough in speaking L2 to their children and not providing them with sufficient linguistic input.

It has to be underlined that sometimes the child may use the other language on purpose, to convey a private message in a manner which is unintelligible to the environment (Saunders 1988: 83-84). Each parent has to decide for themselves whether such use of a different language to exclude a person from a conversation will be tolerated. It has to be taken into consideration that for the majority of people such behaviour will be considered impolite even if the conversation does not concern them directly. On the other hand, a bilingual family cannot be expected to translate every private conversation held in public. The choice regarding communication in the presence of monolinguals depends on the individual circumstances of each family (González 2008).

\subsection{The child rejecting $\mathrm{L} 2$}

It has to be acknowledged that at some point the child may become especially prone to the influence of peers, and their need to blend in with the peer group may force them to refuse to address the parent in a language other than that of the environment. 
In this case, it is advisable to accept the child's feelings and respect their wishes and not to insist on speaking L2 to them in the presence of their friends (Saunders 1988: 25; Szramek-Karcz 2016; Zurer Pearson 2008: 193-194).

Another reason for which the child may reject one of the languages is forcing them to speak it. All the parents can do is to encourage the use of L2 and not to impose it. Pushing the child to use a given language exclusively may have an adverse effect on their motivation (Saunders 1988: 126). It is advisable to look for new ways in which to make L2 appealing to the child. The need to use L2 ought to be driven by intrinsic motivation, which can only be achieved when it evokes positive emotions in the child. So as to achieve it, the parent should not force the child to speak L2, openly assess their ability in it or compare their achievement with the achievement of their bilingual peers (Szramek-Karcz 2014). Even if faced with the rejection of L2 by the child, it is crucial that the parent does not refrain from speaking it completely. The passive knowledge of L2 may still be enhanced, which prevents the language from being forgotten until the child is ready to make active use of it (Saunders 1988: 124-125; Szramek-Karcz 2016).

\subsection{Hostility of the monolingual environment}

Relatives, friends and other people who cannot understand what is being said or who think that bilinguals use different languages to flaunt, may discourage children from their attempts to communicate in L2. Parents should also be careful when seeking professional advice from teachers, doctors and other specialists, as they tend to blame bilingualism for any educational and developmental issues which may occur in both bilinguals and monolinguals (Saunders 1988: 103-104). Parents ought to assure their child that speaking two languages is an asset to be proud of, and that giving up on one of the languages is not going to solve the problem (Zurer Pearson 2008: 193-194). If, however, the parent manages to put forward scientific arguments which will convince the child's immediate environment that being bilingual should be appreciated, such approval may constitute an additional source of motivation for the child. In this respect, the attitude of the child's teachers is of paramount importance. Not only is it reflected in the attitude of the child's peers towards bilinguals, but also they will be able to help overcome difficulties which may result from the languages influencing one another.

\section{The study}

In this section, the results of the analysis of 22 case studies of Polish families will be discussed. It presents how early bilingual education successfully progresses in Polish children in families where one parent uses a language (in all the cases it is English) that is not their native. It also proves that depending on the circumstances and attitudes, each family can develop their own manner of communication.

\subsection{Objectives}

The purpose of the conducted study was twofold. The foremost and major objective was to collect information on the strategies employed by families bringing up their 
children bilingually. Also, parents' opinions on the efficiency of the selected strategies and their children's bilingual development lay within the scope of research. While collecting the data, it was also essential to learn as much as possible about the children's linguistic behaviour. The survey also aimed at establishing the reasons why Polish parents decide to address their children in a foreign language, how they tackle various difficulties and what results they have achieved so far in the process of their children's upbringing.

\subsection{Methodology}

22 Polish families from all over the country agreed to participate in the investigation. The study involved 28 children - 11 boys (39.3\%) and 17 girls (60.7\%). 16 families $(72.7 \%)$ under examination declared having one child and six families -2 children respectively (27.3\%). They were all selected randomly from the 'Intended Bilingualism' Facebook Group. From each family, one parent was interviewed with the use of the questionnaire consisting of twenty questions tackling the following issues: family's linguistic profile, reasons for bilingual upbringing, strategies applied in daily communication, children's linguistic development and attitudes towards bilingualism. The questions considered the factors which may affect the success of early bilingual education in a family and which may be worth inspecting while planning the introduction of the discussed model or strategy. It has to be noted that due to the young age of some children not all the parents were able to address all the questions. Out of the 22 families participating in the study, $17(77.2 \%)$ of them resided in big cities whereas only $5(22.8 \%)$ in towns and villages. In each case, only one parent used a foreign language and the other one used Polish (the dominant language spoken in the community). In 15 families (68.2\%) it was the mother who addressed her off-springs in a foreign language whereas only in 7 cases $(31.8 \%)$ the role was taken by the father. It is essential to underline that in 12 families $(54.5 \%)$ the parents majored in foreign languages, which may have contributed to the thoroughness of the observations and answers given in the survey.

The language used in the investigated families was English. The age of the children spanned from 1 month to 7 years.

Table 1. A profile of investigated children.

\begin{tabular}{|c|c|c|c|c|c|c|c|}
\hline \multicolumn{2}{|c|}{ GENDER } & \multicolumn{2}{|c|}{ RESIDENCE } & \multicolumn{2}{|c|}{ AGE } & \multicolumn{2}{|c|}{ STRATEGY } \\
\hline \multirow{3}{*}{ Male } & \multirow{3}{*}{11} & City & 7 & under 1 & 5 & OPOL & 10 \\
\hline & & \multirow[t]{2}{*}{ Village } & \multirow[t]{2}{*}{4} & $\begin{array}{c}\text { between } 1 \\
\text { and } 4\end{array}$ & 4 & \multirow{2}{*}{ mL@H } & \multirow[t]{2}{*}{2} \\
\hline & & & & over 4 & 2 & & \\
\hline \multirow{3}{*}{ Female } & \multirow{3}{*}{17} & City & 15 & under 1 & 11 & MLP & 6 \\
\hline & & \multirow{2}{*}{ Village } & \multirow{2}{*}{2} & $\begin{array}{c}\text { between } 1 \\
\text { and } 4\end{array}$ & 6 & \multirow{2}{*}{ T\&P } & \multirow{2}{*}{4} \\
\hline & & & & over 4 & $\mathbf{0}$ & & \\
\hline
\end{tabular}




\subsection{Research findings}

After a thorough analysis of all the case studies, it becomes evident that each family is unique due to individual circumstances, and hence they develop their own communication strategy. Although the majority of communication patterns followed by the parents is based on theoretical approaches, there are many factors which influence the extent to which a given strategy can be implemented. Some of them include:

- the need for each of the languages resulting from the expectations of the environment,

- the attitude of the parents, the family and the environment towards addressing the child in L2,

- the linguistic competence of the parent,

- the availability of additional sources of L2,

- the support from educational institutions,

- the age and the attitude of the child,

- the number of children in the family.

All of the factors significantly affect the amount of time when both the parents and the children stay consistent in the use of a given language. The aspect which is common for all the families is the fact that all the parents have made an informed decision to give their children a head start in life. Although there are parents who associate being bilingual with achieving an equal level of attainment in both languages, they all agree that they would be satisfied with the child being able to communicate freely and naturally in L2. The majority of parents perceive bilingual upbringing of their children as a mutual benefit which goes beyond linguistic skills.

The strategies of communication followed by the interviewed families include OPOL and Time and Place. The former is chosen by the parents who attach equal importance to both languages and want the child to receive a considerable amount of input in each of them. The latter strategy is adopted by those parents who do not want to exclude L1 from the communication with their child, or who do not feel comfortable speaking L2 exclusively or almost exclusively. However, since the parents use L1 to communicate with each other, it was not classified as a variation of the Minority Language at Home strategy - Minority Language Immersion. Moreover, in both interviewed double families the environment has influenced the parents to alter their original communication strategy.

As can be seen, among the parents who decide to bring up a bilingual child are not only those whose professional education is connected with languages, but also other parents whose command of L2 allows them to communicate freely in it. The common feature of all the parents is the fact that they also use L2 on a daily basis outside home, usually at work. Those parents who manage to stay consistent in their language choice despite experiencing initial difficulties in addressing the child in L2 and expressing emotions in it, note that they get used to it and it becomes easier with time. Another critical period takes place when the second child is born. First of all, the amount of time which the parents can devote to the linguistic education of the first child is significantly reduced. Secondly, it often happens that children use Polish in communication with each other, which means that the parents can no longer strictly control the linguistic environment of each of the children and the exposure to L2 
of both of them may eventually decrease. Both factors may hinder the development of L2 in the second child. Another challenging moment reported by the parents takes place when the child starts monolingual education in L1 kindergarten or school. At this point the amount of L1 input increases dramatically, which bears considerable consequences on the relation between the languages.

The most common regrets, which can constitute a valuable guideline for those parents who consider implementing bilingual upbringing, concern the fact that L2 could have been introduced earlier and the amount of L2 input could have been higher than provided in reality.

Besides, it can be noted that the Polish society is becoming more and more open to the phenomenon of bilingualism, especially as far as the so-called high-status languages are concerned. Although speaking another language than Polish still draws attention to the speaker, it is often caused by curiosity rather than contempt. Nevertheless, some L2-speaking parents still feel that they are considered to be different, especially those living in towns or villages.

Last but not least, it must be underlined that all the parents have an enthusiastic attitude towards their choice, and they are convinced that what they do can only bring positive results. The parents put the well-being of the family first, and when faced with difficulties, they try to work towards a solution which would take into consideration the needs of both the children and the parents and, at the same time, allow to keep both languages in the child's life alive.

\subsubsection{Reasons for bilingual upbringing}

The results of the study indicate the reasons for the bilingual upbringing that pushed the concerned parents to embark on such a decision. From a number of causes mentioned by the researched families, it appears that there are quite a few of them repeated unanimously. First of all, a foreign language is perceived to be a gift enabling a child to experience the world and different cultures first-hand. 14 out of 22 questioned families (63.6\%) stressed this motive. It is crucial to highlight the fact that 18 families $(81.8 \%)$ also sought the approval of their relatives regarding bilingual upbringing, therefore, before making a decision, other members of respective families, and sometimes even friends, were asked for an opinion.

Another reason for bilingual upbringing voiced by 13 families (59.1\%) concerned their children's use of a foreign language in a free and natural manner. It seems important to them that their kids learn a language not in an imposed mode. In addition, 10 families (45.4\%) mention some practical advantages of speaking more than one language, such as obtaining better qualifications or job opportunities. The parents are also of the opinion that English is bound to open multiple possibilities for their children in the future, i.e. access to a wide range of educational materials or an option of studying abroad. Also, in case of 10 other families (45.4\%), it was broadening the horizons and making life less strenuous thanks to the prior development of foreign language skills to be viewed as another reason supporting the decision of raising children bilingually. In their belief, sparing the children long hours spent studying and providing them with open-mindedness towards the world and other people is a real advantage.

As it occurs from the conducted study, there are also families who are fully aware of the fact that bilingualism positively influences creativity and overall brain function. Mainly those parents who have a significant background in foreign language 
studies claimed they either attended classes devoted to psycholinguistics and discussed various issues pertaining to the study of bilingualism, or read books and papers on the topic. This is true for 7 families (31.8\%). They are aware of the many intellectual profits which living with two languages offers, e.g. an increased number of connections between neurones and better processing of information.

Furthermore, in the case of 4 families $(18.2 \%)$ it is the many trips overseas and the possibility of visiting relatives or friends that pushed them to a decision of bringing up their children bilingually. They voice an undeniable reason that communicating with their children in a foreign language from birth will constitute a solid base to expand from in the future. They point to the role played by the family and the environment and their positive support and attitude towards the objective. 3 families (13.6\%) also raise the issue of learning a foreign language from the youngest age possible, which obviously works for the benefit of the learner and brings better-optimised results, from which a learner will be able to develop further. Hence, the linguistic advantages of early exposure to more than one language are recognised as beneficial to some of the investigated families. Last but not least, in the case of 2 families ( $9 \%$ ) their off-spring was born abroad; therefore the necessity of maintaining the foreign language proved to be an urgent need. Negligence or indifference to the country of birth and its language would be considered shameful or unfair. In this situation, the parents' main aim is to enable their children fluid communication in L2 as soon as possible. In their view, the most critical aspects of bilingual upbringing include consistency on the part of the parent and their absolute fluency and proficiency in a chosen language. The parents consider the latter to be particularly significant when they themselves are the main source of L2. In the long run, they plan to teach their children to read and write in L2, and if there exists such a possibility, send them to a bilingual school.

Table 2. Reasons for selecting a bilingual model of upbringing.

\begin{tabular}{|l|c|c|}
\hline \multicolumn{1}{|c|}{ Reasons } & Number of families & \% \\
\hline Experiencing the world and other cultures & 14 & 63.6 \\
\hline Using a foreign language in a free and natural manner & 13 & 59.1 \\
\hline obtaining better qualifications or job opportunities & 10 & 45.4 \\
\hline Broadening the horizons & 10 & 45.4 \\
\hline Improving creativity and overall brain function & 7 & 31.8 \\
\hline Trips overseas and visiting relatives / friends & 4 & 18.2 \\
\hline Learning a foreign language from the youngest age possible & 3 & 13.6 \\
\hline The child being born abroad & 2 & 9 \\
\hline
\end{tabular}

\subsubsection{Strategies applied in a bilingual upbringing}

Of the four communication strategies applied by the families involved in the study, One Parent - One Language (OPOL) seems to be the most popular. 10 families 
(45.4\%) out the 22 investigated considered it as the most effective in their contexts. 6 families (27.3\%) mention employing Mixed Language Policy (MLP) on a daily basis, and they conclude that the strategy is effective as it allows for the interchangeable and free use of two languages. Time and Place (T\&P) occupies the third position in popularity although only 4 families (18.2\%) admitted its frequent use in everyday communication with their children. Last but not least, only 2 families $(9.1 \%)$ out of those 22 questioned utilise Minority Language at Home. This strategy seems less adequate in our study as it is basically applied in immigrant families.

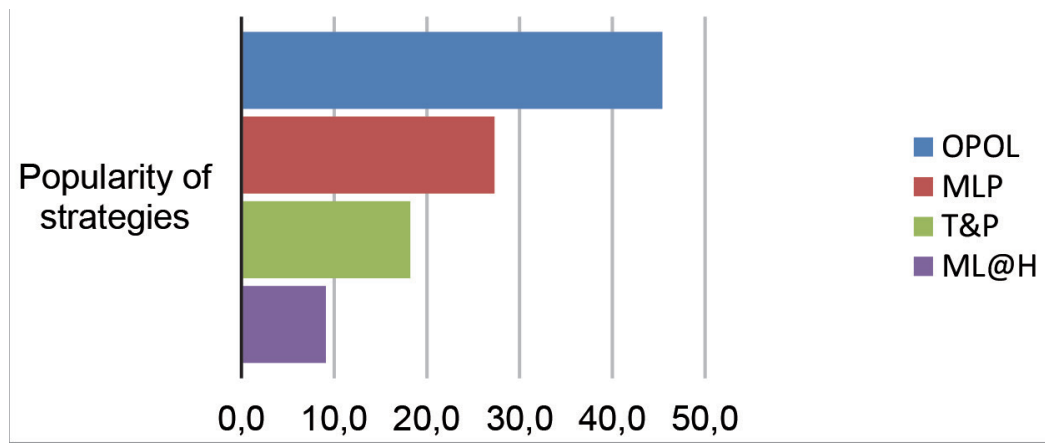

Figure 1. Popularity of strategies.

\subsubsection{Children's linguistic development}

The communicative approach, which focuses on how language is used practically, emphasises the ability to communicate the message concerning its meaning, instead of concentrating exclusively on grammatical perfection or phonetics. Therefore, the understanding of the second language is evaluated in terms of how much the learners have developed their communicative abilities and competencies. Following this line of argument, the most important outcome of language acquisition is the ability to communicate. It was also the main reason for which the families that participated in the survey decided to apply bilingual upbringing - to render possible communication between them, their children, other relatives and friends. The analysis of collected findings has shown that, in general, bilingual upbringing has proved successful.

The methods applied by the families occurred to be effective not only with regard to communicative skills, but also general linguistic skills. All the families (100\%) claim to be content with their children's linguistic performance. Among them 17 (77.3\%) describe themselves as very satisfied and $5(22.7 \%)$ as satisfied. Regarding the children's vocabulary, it has to be stated that it was also greatly appreciated. In this case, again only 2 parents $(9 \%)$ claimed not to be happy. Among the remaining families $15(68.2 \%)$ are very satisfied, $3(13.6 \%)$ satisfied, and the remaining $2(9 \%)$ refrained from answering the question.

In addition, to provide the full picture concerning children's linguistic behaviour, code-switching, lexical transfer, and grammatical transfer were also included in the questionnaire. Only 2 families did not answer the question. 15 parents elaborated on the topic and provided some examples from their children's speech. Code-switching 
was observed in exactly 15 cases (68.2\%), lexical transfer in 10 families $(45.4 \%)$ and grammatical transfer in 6 families $(27.3 \%)$. Another 6 families $(27.3 \%)$ noticed other examples of linguistic behaviour. It is imperative to stress that not all the families provided concrete responses concerning their children's linguistic behaviour. The examples outlined below resulted from extensive discussions with selected families who were able to identify the aforementioned linguistic phenomena.

The most popular and vivid example of behaviour referred to code-switching, which was present in all possible forms, i.e. shifting individual words, phrases or even sentences. The parents unanimously noticed that this occurs when their children cannot find a proper word in the language used or when a concept can be more easily expressed in another language. Lexical transfer was the second most common behaviour scrutinised in the research group. Grammatical transfer proved to be less ubiquitous than lexical transfer. Also, some other types of behaviour were highlighted by the parents under study. Two parents pointed out that their children codeswitch only while playing or watching cartoons, probably because they are aware of the fact that both parents speak those languages and will understand them without difficulty. Three children, according to their parents' observations, would utter words, one after another, in both languages. Last but not least, in one case the whole family applied lexical transfer on a daily basis while communicating with one another.

Table 3. Children's linguistic behaviour.

\begin{tabular}{|c|c|c|}
\hline \multirow{2}{*}{ Children's linguistic behaviour } & \multicolumn{2}{|c|}{ Popularity } \\
\hline & Number of families & $\%$ \\
\hline Code-switching & 15 & 68.2 \\
\hline Lexical transfer & 10 & 45.4 \\
\hline Grammatical transfer & 6 & 27.3 \\
\hline Other & 6 & 27.3 \\
\hline
\end{tabular}

\subsubsection{Attitudes towards bilingual upbringing}

All the participating families seem to be very satisfied with the employed strategies and their outcomes. The process of bilingual upbringing, although a bit artificial initially, appeared to be efficient despite some hardships and inconsistencies. All the researched families admitted to being enthusiastic about their choice whereas they indicated on many occasions that other members of the family did not necessarily notice the benefits instantly and exhibited a dose of scepticism. They thought it was impossible for such young children to achieve what they consider to be true bilingualism: two languages equal in all respects, including the ability to think abstractly in each of them. The grandparents occurred the most reluctant initially and did not believe in the success of bilingual upbringing in the monolingual conditions. Now, having seen that the parents' strategy of communication brings desirable effects, the grandparents are happy that their grandchildren are becoming increasingly compe- 
tent in both languages. In other words, they are impressed with the effects, which made them change their mind.

As many as 15 families (68.2\%) experienced some unpleasant situations connected with their decision to raise the off-spring bilingually and 6 families $(27.3 \%)$ out those felt initially discouraged by unfavourable comments from the surrounding environment because of the choice of language. Besides 4 families (18.2\%) met with the statement that bilingualism causes confusion and delayed speech development which, only to some extent, led to the loss of confidence and the lack of success in their actions. Thus, as can be observed, there are still opponents of bilingual upbringing and it might be hard, especially at the initial stage, to get full support of the family. It should be stressed that most families became convinced thanks to the results they managed to achieve, and now they have had no problem with addressing their children in L2 ever since.

In general, a tendency can be noticed among parents to encourage other potential families to early bilingual education. Although most parents involved in the study already have to face some difficulties connected with their choice, they still receive constant support and encouragement from their friends whose children are older than theirs and who also bring them up bilingually. They are the source of valuable advice for the parents new to the concept, and their achievements allow them to see where their efforts and consistency can further lead them. Hence, all the researched families voiced the need to popularise bilingual upbringing as well as establishing and joining support groups for parents of bilingual children. This, in their viewpoint, will make the subject more accessible. Ultimately, such a possibility will help overcome fear and positively affect consistency in one's choice.

Nowadays, that English has become the international language, bilingual upbringing ought to be promoted and not looked down on. 14 families $(63.6 \%)$ decided to raise their children bilingually not only because they realise how essential it is to be able to speak foreign languages, but also because they had done some background reading about bilingualism. They are aware of the positive influence of bilingualism on the brain function. Although they are aware of the fact how difficult it is to achieve equal competence in both languages, they advise other parents, who weigh the pros and cons of bilingual upbringing, not to hesitate, as their children can only benefit from such an approach. As soon as they start to see the first signs of success, they will feel rewarded and motivated to stay consistent in their choice.

12 families $(54.5 \%)$ articulate the complexity of the process; however, they also observe that no language course can facilitate progress in the same way as daily exposure to L2 at home. Only 10 parents (45.4\%) point out the fact that addressing a child in a language other than Polish in public places is unusual; hence they automatically refrain from speaking their L2 so as not to draw attention to themselves. Consequently, we observe how influential the attitude of society might be. All the parents got used to the fact that they stand out from the crowd, even if it involves receiving occasional unfavourable looks or comments.

On the other hand, some people put forward an argument that in case of such a mode of bilingual upbringing there is no natural motivation to learn a language, namely the need to communicate with the parent, as the child realises that the parent also speaks L1. Even in mixed marriages parents often understand the native language of their spouse and sometimes are fluent in it, and yet the child does not question the pattern of communication followed in the family. The majority of researched 
parents consider it crucial to be consistent and persist in one's decision despite potential difficulties.

As mentioned earlier, 6 families $(27.3 \%)$ of those questioned have applied bilingual upbringing to the younger children they have, and 5 other families $(22.7 \%)$ also imply the significance of planning bilingual upbringing of their children ahead as well as setting some new goals to pursue. Also, as many as 10 families (45.4\%) assume the possibility of introducing another foreign language once their children have attained a relatively high level of competence in the first language they are being exposed to. In 2 cases $(9 \%)$, as parents are multilingual and speak several languages, they had to decide as to which language to pass on to their children first.

\section{Conclusion}

The linguistic upbringing of young children is complex and demanding. Hence, with the view to the obtained findings, it might be postulated that its success is largely dependent on parents' persistence and dedication.

In this paper, the intention was to critically discuss and evaluate the effectiveness of bilingual upbringing in a monolingual context where one of the parents speaks an L2 to their child. It is a new phenomenon observed in Poland among monolingual families. It evokes a lot of emotion and raises controversy to such an extent that it is even labelled as dangerous to a child (Szramek-Karcz 2016). However, as can be seen from the conducted study and analysed cases, more and more parents adopt the model with the hope of raising their children bilingually although they reside in a monolingual environment and none of them is a native speaker of the target language.

The analysis of the findings proved that such an approach does not lead to confusion or further problems in communication. The children can communicate not only with their parents and the parents' families in the parents' native languages, but also function well in the target language. The parents have to believe in the idea of bilingualism if they really want their children to become bilingual, and they should motivate their children in order to achieve the goal. The interviews were warmly welcomed by the parents and evaluated as stimulating to further work on the strategy. The parents willingly provided their thorough responses to the posed questions regarding the everyday life of their family. The methods the concerned parents successfully employ are not only efficient enough, but also satisfying. It seems crucial at this point not to forget about the importance of patience and persistence. In some cases, it was requisite to wait a more extended period until positive results occurred observable. This only proved a well-known truth that children start producing the language at different stages of their development and no rule as such applies in this case; hence those who show the first symptoms of their linguistic behaviour in the target language later are not worse or retarded. It needs to be indicated at this point that if we want this approach to result in the child becoming a bilingual speaker, the input should be frequent and linguistically correct, with the environment affording many opportunities to use the language.

Because parents are role-models for their children and the major source of input, both their language and their attitude play a crucial role. As can be seen from the 
collected findings, it is impossible to choose one method suitable for all the families. Nonetheless, some of the employed strategies can be indicated as not only productive but also efficient. The most frequently applied OPOL strategy proved very successful among the examined families. In most cases it leads to the efficient acquisition of at least two languages, even if the strict separation of the languages is not respected. From the conducted interviews, it has become apparent that the parents are also contented about the opportunity to ascribe one language to one person, which makes the differentiation between languages clearer.

While some may still postulate that introducing another language through the application of the model is confusing and leads to adverse effects in children, this common myth should be debunked as the collected evidence denies it. This way of bilingual upbringing turned out to be profitable and favourable in all the studied cases. Children raised bilingually are at an advantage when compared to monolinguals, and although the process is demanding for both parents and children, it is worth taking the chance, especially when the final effect is so rewarding.

\section{References}

Arnberg, L. 1987. Raising Children Bilingually: The Pre-School Years. Clevedon: Multilingual Matters.

Auer, P. \& Li Wei. 2007. Handbook of Multilingualism and Multilingual Communication. Göttingen: Hubert and Co.

Baker, C. 2010. Foundations of Bilingual Education and Bilingualism. Bristol: Multilingual Matters.

Baker, C. 2014. A Parents' and Teachers' Guide to Bilingualism. Bristol: Multilingual Matters.

Cook, V. 2002. Background to the L2 user. In: Cook, V. (Ed.), Portraits of the L2 User. Bristol: Multilingual Matters. 1-28.

De Houwer, A. 2009a. Bilingual First Language Acquisition. Bristol: Multilingual Matters.

De Houwer, A. 2009b. An Introduction toBilingual Development. Bristol: Multilingual Matters.

Döpke, S. 1986. Discourse structures in bilingual families. In Journal of Multilingual and Multicutural Development, 7(6), 493-507.

Festman, J., G. J Poarch \& J. M. Dewaele 2017. Raising Multilingual Children. Bristol: Multilingual Matters.

González, J.M. (Ed.). 2008. Encyclopaedia of Bilingual Education. Thousand Oaks, CA: Sage.

Grosjean, F. 2009. What parents want to know about bilingualism. The Bilingual Family Newsletter, 26 (4), 1-6.

Grosjean, F. 2010. Bilingual: Life and Reality. Cambridge, MA: Harvard University Press.

Grosjean, F. and P. Li. 2012. The Psycholinguistics of Bilingualism. New York: Wiley.

Gupta, A. F. 1994. The Step-Tongue: Children's English in Singapore. Clevedon: Multilingual Matters.

Harding, E. \& P. Riley 1986. The Bilingual Family. A Handbook for Parents. Cambridge: Cambridge University Press

Hickey, T. M. 2013. Early bilingual education. In: C. A. Chapelle (Eds). The Encyclopedia of Ap plied Linguistics. Oxford: Blackwell Wiley. 
Jimenez. M. I. 2011. Mut zur Mehrsprachigkeit. So erziehe ich mein Kind in einer Fremdoder Zweitsprache. Engelschoff: Verlag auf dem Ruffel.

Jessner, U. 2008. Teaching third languages: findings, trends and challenges. Language Teaching 41(1), 15-56.

Komorowska, H. 2005. Metodyka nauczania języków obcych. Warszawa: Fraszka Edukacyjna.

Komorowska, H. 2014. Analyzing linguistic landscapes. A diachronic study of multilingualism in Poland. In: A. Otwinowska and G. De Angelis (Eds.) Teaching and Learning in Multilingual Contexts: Sociolinguistic and Educational Perspectives. Bristol: MultilingualMatters, 19-31.

Kurcz, I. (Ed.). 2006. Psychologiczne aspekty dwujęzyczności. Gdańsk: Gdańskie Wydawnictwo Psychologiczne.

Lanza, E. 1997. Language Mixing in Infant Bilingualism: A Sociolinguistic Perspective. Oxford: Clarendon Press.

Li Wei. 2011. The early acquisition of English as a second language. The case of young Chinese learners of English in Britain. In: A. De Houwer \& A. Wilton (Eds.) English in Europe Today: Sociocultural and educational perspectives. Amsterdam: John Benjamins Publishing Company.

Olpińska-Szkiełko, M. 2013. Nauczanie dwujęzyczne w świetle badań glottodydaktycznych. StudiaNaukowe 10. IKLA Publishing House, University of Warsaw.

Otwinowska, A. 2015. Cognate Vocabulary in Language Acquisition and Use: Attitudes, Awareness, Activation. Bristol: Multilingual Matters.

Paradowski, M. \& M. Michałowska 2016. Establishing a Bilingual Home: Parents' Perspective on the Effectiveness of the Adopted Communication Strategies. Lingwistyka Stosowana, 17(2), 43-65.

Ramjoue, B. 1980. Guidelines for Children's Bilingualism. Paris: Association for American Wives of Europeans.

Romaine, S. 1995. Bilingualism. Oxford: Oxford University Press

Rosenback, R. 2015. Time and place - T and P as a family language strategy. Multilingual Parenting. http://multilingualparenting.com/2015/04/29/time-and-place-as-a-family-language-strategy/

Rosenback, R. 2017. Should parents always speak their native language with their children? https://multilingualparenting.com/2017/01/29/qa-should-parents-always-speak-their-native-language-with-their-children/

Romanowski, P. 2016. Some Reflections on the Idiosyncrasy of Bilingual Education in Secondary Schools in Poland. In: Grucza, S., Olpińska-Szkiełko, M., Romanowski, P. (Eds.), Bilingual Landscape of the Contemporary World. Frankfurt: Peter Lang GmbH.

Saunders, G. 1988. Bilingual Children: From Birth to Teens. Bristol: Multilingual Matters

Singleton, D. and L. Aronin. 2007. Multiple language learning in the light of the theory of affordances. International Journal of Innovation in Language Learning and Teaching 1(1), 83-96.

Szramek-Karcz, S. 2014. Non-Native Bilingualism in Poland - a formulation of the problem. Linguistica Silesiana 35, 293-303.

Szramek-Karcz, S. 2016. The Success of Non-Native Bilingualism in Poland. Lingwistyka

Stosowana 17: 2/2016, 93-102.

Zurer Pearson, B. 2008. Raising a Bilingual Child. New York: Living Language. 


\section{Appendix 1}

\section{Bilingual upbringing in Poland - a case study}

\section{Part 1}

\section{Linguistic profile of the family}

1. How old is your child?

2. Which language(s) is your child exposed to? Who is the source of language?

3 . How long has your child been exposed to the language?

4. Which language do you use to communicate with your partner?

5. What level of competence in the second language have you achieved yourself?

6. Have you majored from a linguistic course of studies (Foreign Language Studies, Applied Linguistics, Teaching Foreign Languages, etc.)?

7. What level of competence in the second language have other members of the family achieved (your partner, child's grandparents, extended family)?

8. In which language do you address your child in the presence of people who do not understand the second language (e.g. family, child's friends)?

9. How much exposure does your child receive in each language on a daily basis?

10. Do you follow any particular strategy of communication in the family (e.g. OPOL, mL@H)?

11. Are you consistent in speaking the second language to the child?

12. Is your child literate in the second language?/Do you plan to teach your child to read and write in the target language?

\section{Part 2}

\section{Attitudes towards bilingualism}

1. Why did you decide to raise your child with two languages?

2. What level of competence in the second language would you like your child to achieve?

3. What is your attitude towards bilingual upbringing? What's the attitude of your family?

4. Have you ever heard any unfavourable comments regarding bilingualism?

5. Have you ever faced any unfavourable opinions as regards non-native bilingualism?

6. Have you ever faced any unpleasant reactions of people while addressing the child in the foreign language (e.g. in public places)?

7. What advice would you give to those parents who are interested in introducing non-native bilingualism in their family?

8. How are you going to support your child's linguistic development in the future? 